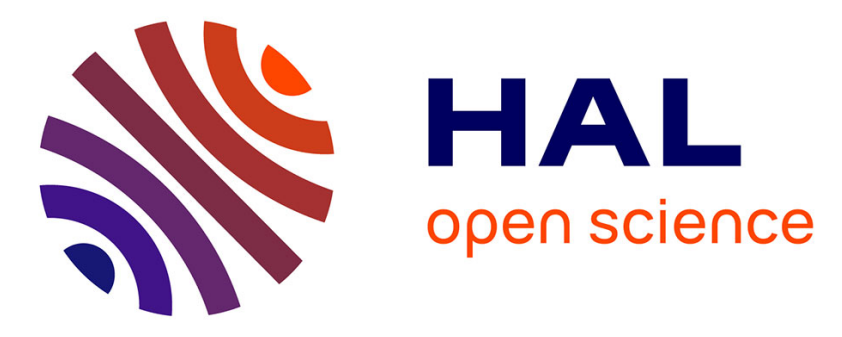

\title{
Redox-active phosphines: synthesis and crystal structures of palladium(II) complexes of a metallaphosphine in two different oxidation states.
}

Ayham Tohmé, Stéphanie Labouille, Thierry Roisnel, Vincent Dorcet, Duncan Carmichael, Frédéric Paul

\section{To cite this version:}

Ayham Tohmé, Stéphanie Labouille, Thierry Roisnel, Vincent Dorcet, Duncan Carmichael, et al.. Redox-active phosphines: synthesis and crystal structures of palladium(II) complexes of a metallaphosphine in two different oxidation states.. Dalton Transactions, 2014, 43 (19), pp.7002-5. $10.1039 / \mathrm{c} 4 \mathrm{dt} 00455 \mathrm{~h}$. hal-01066258

\section{HAL Id: hal-01066258 https://hal.science/hal-01066258}

Submitted on 19 Sep 2014

HAL is a multi-disciplinary open access archive for the deposit and dissemination of scientific research documents, whether they are published or not. The documents may come from teaching and research institutions in France or abroad, or from public or private research centers.
L'archive ouverte pluridisciplinaire HAL, est destinée au dépôt et à la diffusion de documents scientifiques de niveau recherche, publiés ou non, émanant des établissements d'enseignement et de recherche français ou étrangers, des laboratoires publics ou privés. 


\title{
Redox- active phosphines: synthesis and crystal structures of palladium (II) complexes of a metallaphosphine in two different oxidation states.
}

\author{
Ayham Tohmé ${ }^{a}$, Stéphanie Labouille ${ }^{b}$, Thierry Roisnel ${ }^{a}$, Vincent Dorcet ${ }^{a}$, Duncan Carmichael \\ $b_{*}$ and Frédéric Paul ${ }^{a *}$
}

${ }^{a}$ Institut des Sciences Chimiques de Rennes, CNRS (UMR 6226) Université de Rennes 1, Campus de Beaulieu, 35042 Rennes Cedex (France), Fax: O(033)223236939, E-mail: frederic.paul@univ-rennes1.fr

${ }^{b}$ Laboratoire Hétéroéléments et Coordination, CNRS (UMR 7653), Ecole Polytechnique, 91128 Palaiseau Cedex, France, Fax: O(033)169334440, E-mail: duncan.carmichael@polytechnique.edu

The redox- active metallaphosphine $\left[\mathrm{Fe}(\mathrm{dppe})\left(\eta^{5}-\mathrm{C}_{5} \mathrm{Me}_{5}\right)\left(\mathrm{C} \equiv \mathrm{C}-\mathrm{PPh}_{2}\right)\right]$ reacts with $\left[\operatorname{Pd}(1,5-\operatorname{cod}) \mathrm{Cl}_{2}\right]$ give mono- and bis- phosphine complexes as a function of stoichiometry, and these complexes provide a stable redox- active platform which allows reversible one- electron $\left\{\mathrm{Fe}(\mathrm{II}) \rightarrow \mathrm{Fe}^{+}(\mathrm{III})\right\}$ oxidations within the palladium coordination sphere.

Fine control of architecture and the ability to generate quite specific electronic environments ${ }^{1}$ means that phosphines are exceptionally widely used in many metal- catalysed processes, ${ }^{2}$ and their versatility has driven recent research into areas as varied as self- assembling phosphines for enantioselection, ${ }^{3}$ supramolecular phosphines allowing unprecedented catalytic selectivities, ${ }^{4}$ and hybrid chemical/biological phosphine- containing systems. ${ }^{5}$ However, there has been comparatively little recent interest in the class of redox- active phosphines, ${ }^{6}$ which should constitute an unusual class of "non- innocent" ligands ${ }^{7,8}$ and have been invoked inter alia for the switching of catalytic processes. ${ }^{9}$ We have recently demonstrated that phosphorus centres and redox- active organoiron endgroups can communicate strongly if linked through molecular wires such as acetylenes, and that oxidation of the $\mathrm{Fe}$ (II) endgroup in $\mathbf{1}$ provokes significant reactivity at the phosphorus centres (Scheme 1). ${ }^{10}$ This unusual behaviour prompted a study of the coordination chemistry of this metallaphosphine towards Pd(II) centres.

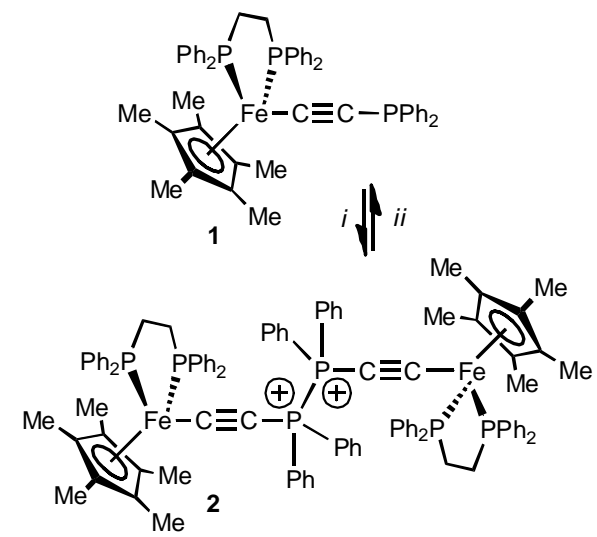

Scheme 1: Redox switching of metallaphosphine 1. Reagents: $i$ : $[\mathrm{FcH}]\left[\mathrm{PF}_{6}\right], 2$ eq., $\mathrm{CH}_{2} \mathrm{Cl}_{2}$, $20^{\circ} \mathrm{C}, 1 \mathrm{~h}$; $i$ : $\left[\mathrm{CoCp}_{2}\right] 3$ eq., $\mathrm{CH}_{2} \mathrm{Cl}_{2}, 20^{\circ} \mathrm{C}, 1 \mathrm{~h}$. 

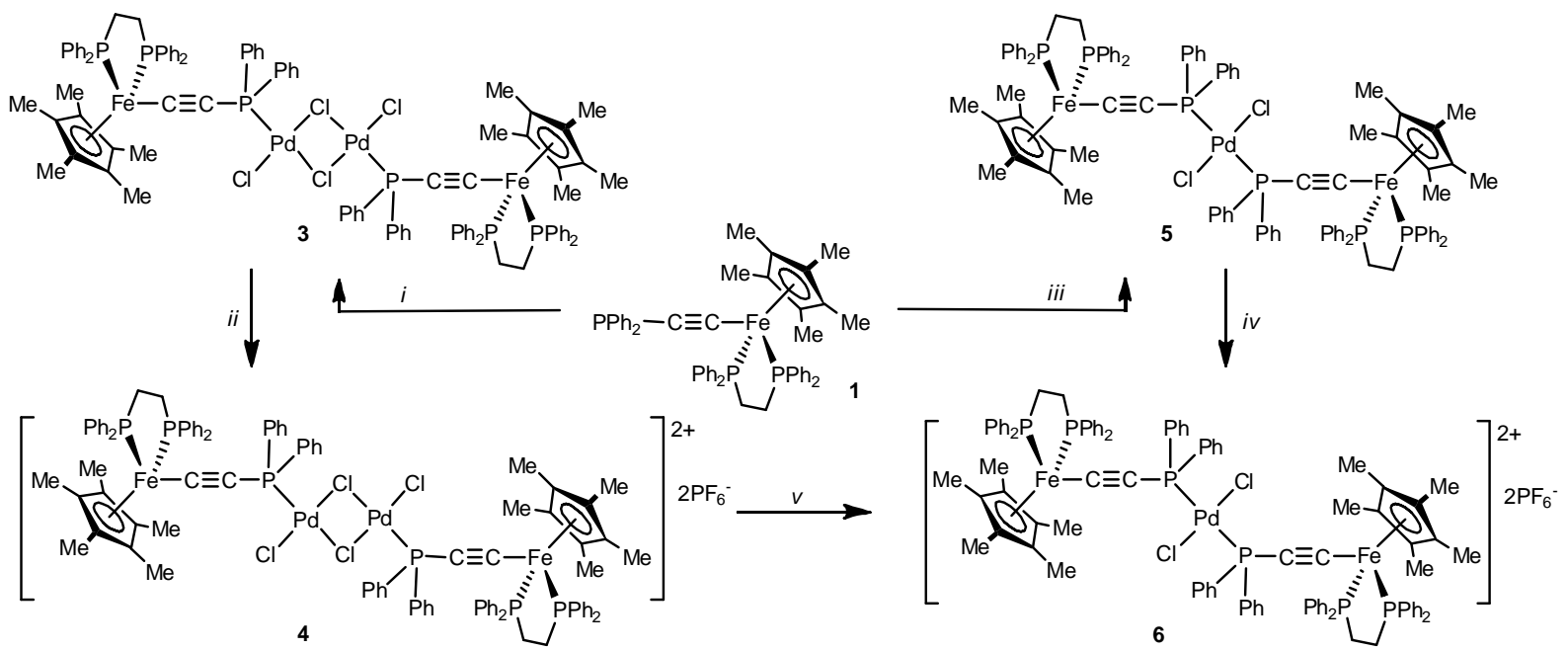

Scheme 2: Coordination chemistry of $\mathbf{1}$ and redox reactivity of the resulting $\mathrm{Pd}(\mathrm{II})$ complexes 3 and 5. Reagents and conditions: $i$ : $\left[\mathrm{PdCl}_{2}(1,5\right.$-cod) $]$ (1.0eq.), $\mathrm{CH}_{2} \mathrm{Cl}_{2}, 15 \mathrm{~h}, 97 \%$; ii: $[\mathrm{FcH}]\left[\mathrm{PF}_{6}\right], \mathrm{CH}_{2} \mathrm{Cl}_{2}, 1 \mathrm{~h},>98 \%$; iii: $\left[\mathrm{PdCl}_{2}(1,5\right.$-cod) $]$ (0.5eq.), $\mathrm{CH}_{2} \mathrm{Cl}_{2}, 15 \mathrm{~h}, 96 \%$; iv: $[\mathrm{FcH}]\left[\mathrm{PF}_{6}\right], \mathrm{CH}_{2} \mathrm{Cl}_{2}, 1 \mathrm{~h},>98 \%$; v: Compound 2 (1.0eq.), $\mathrm{CD}_{2} \mathrm{Cl}_{2}, 15 \mathrm{mn},>95 \%$.

Reaction of the diamagnetic metallaphosphine 1 with one equivalent of $\left[\mathrm{PdCl}_{2}(1,5-\mathrm{cod})\right]$ gives a near- quantitative isolated yield of a blue, air-stable dimeric complex $\left[\mathrm{Pd}_{2} \mathrm{Cl}_{4}(\mathbf{1})_{2}\right] \mathbf{3}$ that shows a classical trans- phosphine configuration about a butterfly- configured $\mathrm{Pd}_{2} \mathrm{Cl}_{4}$ core (Fig 1, in purple). ${ }^{11}$ The metalloligand undergoes moderate structural changes upon coordination, with the most significant differences being associated with the alkyne linker (Fig 1). The $\mathrm{C} \equiv \mathrm{C}$ and $\mathrm{C}-\mathrm{P}$ bond lengths in $\mathbf{3}$ are slightly longer and shorter respectively than those normally found for simple $\mathrm{PdCl}_{2}$ - coordinated alkynyl-(diaryl phosphines) ${ }^{12}$ and the alkynyl $v_{\mathrm{C} \equiv \mathrm{C}}$ stretch falls from 1964 to $1930 \mathrm{~cm}^{-1}$, all of which imply an increased contribution from an iron-vinylidene resonance hybrid. ${ }^{13}$
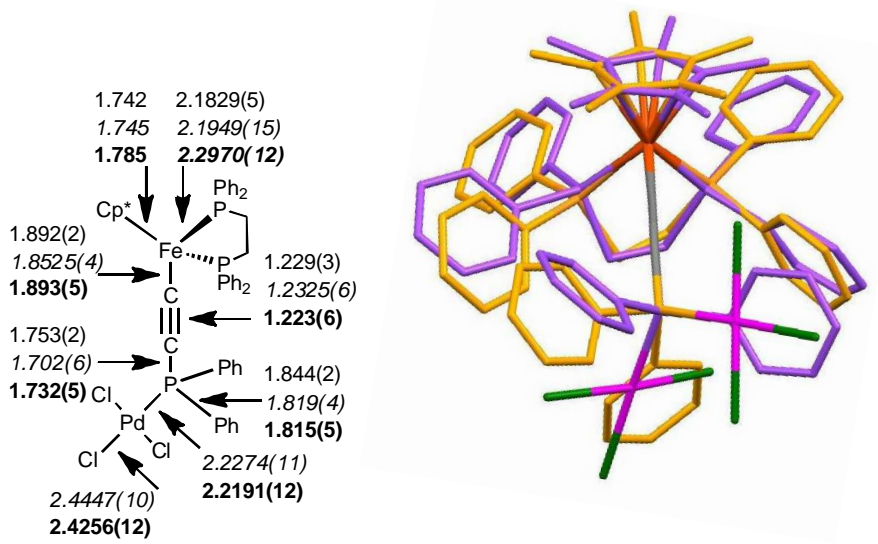

Fig 1. Left: Superimposed X-ray- structures showing one half of each of the dimers forming the 3, 4 redox couple, showing ligand superstructure for the neutral complex 3 (purple) and its oxidation product 4 (gold). ( $\mathrm{Pd}$ in magenta, $\mathrm{Fe}$ in orange, $\mathrm{Cl}$ in green). See supplementary for individual depictions of these complexes. Right: X-ray structural changes upon passing from free ligand 1 (plain text) to neutral dimer 3 (italic) and dication 4 (bold). Values are averaged over chemically equivalent sites. 
The cyclic voltammogram for 3 shows two closely spaced reversible oxidations at +0.16 and $+0.25 \mathrm{~V}$ (both showing $\Delta \mathrm{Ep}=85 \mathrm{mV}$ in $\mathrm{CH}_{2} \mathrm{Cl}_{2}$ vs $\mathrm{SCE}$ ), which lie within a wellprecedented window for the organoiron endgroup; ${ }^{13}$ bulk chemical oxidation using $[\mathrm{FcH}]\left[\mathrm{PF}_{6}\right]^{14}$ cleanly and near- quantitatively gave the black, air sensitive, dichloromethanesoluble 4, whose formulation as the corresponding double oxidation product was confirmed by an X-ray structural analysis (Fig 1, gold). The crystallographic data confirm an essentially iron- based oxidation, which is reflected in an elongation of $a$ ) the mean Fe-P distances to the dppe ligand from 2.1949 to $2.2970 \AA(+4.7 \%)$ and $b$ ) the mean $\mathrm{Fe}-\mathrm{Cp}^{*}{ }_{\text {centroid }}$ distances from 1.745 to $1.785 \AA(+2.2 \%) .{ }^{15}$ The oxidation has a significantly smaller effect upon the palladium coordination sphere: a slight shortening of the mean Pd-P distance, from $2.2274(11)$ to $2.2191(12) \AA(-0.4 \%)$ and a modest $(0.8 \%)$ shortening in the trans- Pd-Cl distance from $2.4447(10)$ to $2.4256(12) \AA$ are observed, ${ }^{16}$ whilst the sum of the angles made by the organic groups at the Pd-coordinated phosphorus also rises only modestly from 317.6 to $321.8^{\circ}$. The dimeric palladium core of the molecule can be expected to act as "spacer" between the two oxidised $\left[\operatorname{Pd}\left(\mathbf{1}^{+}\right)\right]$components and an Evans determination ${ }^{17}$ of a room temperature magnetic moment of $2.21 \pm 0.1 \mathrm{BM}$ at $293 \mathrm{~K}$ is consistent with a ditopic diradical featuring two non-interacting spins. ${ }^{18}$

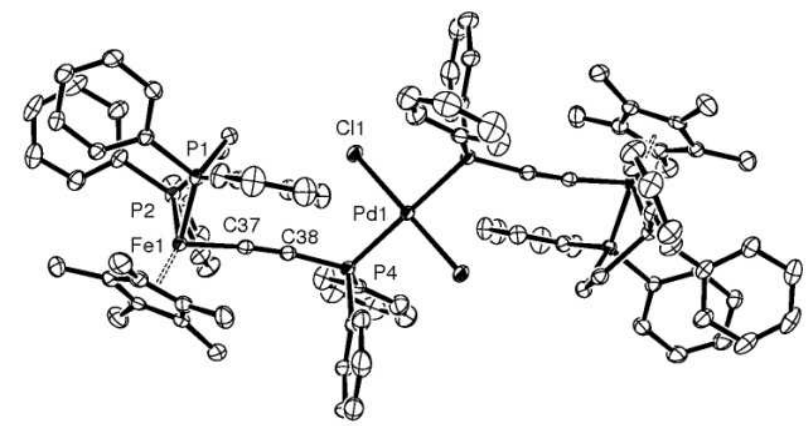

Fig. 2: X-ray structure of the neutral monomeric Pd complex 5.

Palladium dimers of type 3 are excellent sources of both homo- and heteroleptic $\left[\mathrm{PdCl}_{2} \mathrm{~L}_{2}\right]$ complexes $^{19}$ and 5, which offers the possibility of two- electron redox chemistry within a Pd coordination sphere, was found to be accessible through either reaction of two equivalents of $\mathbf{1}$ with the palladium bridged dimer $\mathbf{3}$, or by simple reaction of two equivalents of $\mathbf{1}$ with $\left[\mathrm{PdCl}_{2}(1,5-\mathrm{cod})\right]$ (Scheme 2). Single crystals of the purple, air-stable trans- configured 5 revealed metallaphosphine ligands that are very similar to those in $\mathbf{3}$ and Pd-P distances

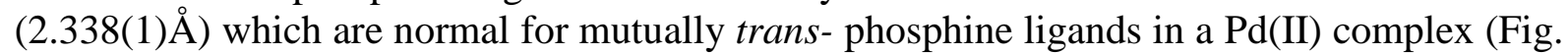
2). DFT data from a model for $\mathbf{5}^{20}$ (Fig. 3) show a sharp increase in the NBO- calculated positive charge at the $\mathrm{Pd}-$ bound phosphorus $(+0.62)$ and a significant rise at the ironcoordinated alkyne carbon $(+0.10)$ upon coordination but only negligible changes $(<0.04)$ elsewhere. Again, cyclic voltammetry showed closely- spaced reversible oxidation waves $\left(\mathrm{E}_{1 / 2}^{1}=-0.02 \mathrm{~V}, \mathrm{E}_{1 / 2}^{2}=0.11 \mathrm{~V}\right)$ and chemical oxidation using two equivalents of $[\mathrm{FcH}]\left[\mathrm{PF}_{6}\right]$ provided a black, air-sensitive product, $\mathbf{6}$. Crystals suitable for a diffraction study were not obtained, but comparison of the very similar ${ }^{1} \mathrm{H}$ NMR data for $\mathbf{4}$ and $\mathbf{6},{ }^{21}$ and an Evans determination showing a value of $2.42 \pm 0.1 \mathrm{BM}(298 \mathrm{~K})$ that is again classical for two unpaired electrons, ${ }^{18}$ imply a bis-Fe(III) complex showing little spin-spin coupling across the palladium centre. A DFT comparison of NBO charge distributions in models ${ }^{14}$ for 5 and $\mathbf{6}$ confirms an iron based oxidation $\left(\delta \mathrm{Q}_{\mathrm{Fe}(5 \rightarrow 6)}=+0.36\right)$ that causes significant changes in charge at the linker atoms $\left(\delta_{\mathrm{Q}(\mathrm{Fe}-\mathrm{C})}=-0.13 ; \delta_{\mathrm{Q}(\mathrm{P}-\mathrm{C})}=+0.21\right)$ but significantly smaller effects at phosphorus and at palladium $\left(\delta_{\mathrm{Q}(\mathrm{P}, \mathrm{Pd})}<0.02\right)$. 

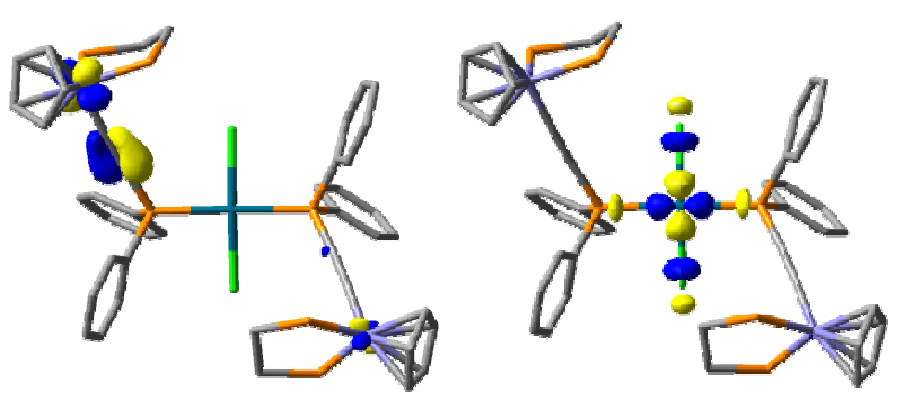

Fig 3: The B3PW91 calculated HOMO (left) and LUMO (right) for $\left[\mathrm{PdCl}_{2} \mathrm{~L}_{2}\right]$, (L= $\left.\mathrm{FeCp}\left\{\mathrm{H}_{2} \mathrm{PCH}_{2} \mathrm{CH}_{2} \mathrm{PH}_{2}\right\} \mathrm{C}_{2} \mathrm{PPh}_{2}\right)$, a model for 5. Calculated HOMO- LUMO gap: 3.05eV.

The individual redox steps that occur within the bound couples $\mathbf{3 , 4}$ and $\mathbf{5 , 6}$ appear to be wellbehaved, but the chemical reversibility of the system as a whole clearly also rests upon the integrity of the dissociated ligands. The stability of $\mathbf{1}$ is established but our previous study has shown that the iron (III) proligand 2' normally exists as a $1,1^{\prime}$ - (biphosphine)dication $\mathbf{2}^{10}$ (Scheme 3); this raises the undesirable possibility of the transient dissociation of 4 with subsequent dimerisation of the $\mathrm{Fe}$ (III) ligand monomers to generate a 1,1'(biphosphine)dication 2 reservoir and a ligand- deficient solution that deposits $\left[\mathrm{PdCl}_{2}\right]$. Experiments conducted upon isolated 1,1'-(biphosphine)dication 2 and $\left[\mathrm{PdCl}_{2}(1,5-\mathrm{cod})\right]$ indicate that this mixture cleanly generates complex $\mathbf{4}$ (with 2eq of $\mathrm{Pd}$ ) or $\mathbf{6}$ (with 1eq of Pd), and therefore confirm that ligand dissociation from both systems is reversible. The most likely mechanism involves the transient dissociation of the P-P bond to generate the $\mathrm{Fe}$ (III) proligand 2, ${ }^{10}$ prior to capture by the Pd centre (Scheme 3).

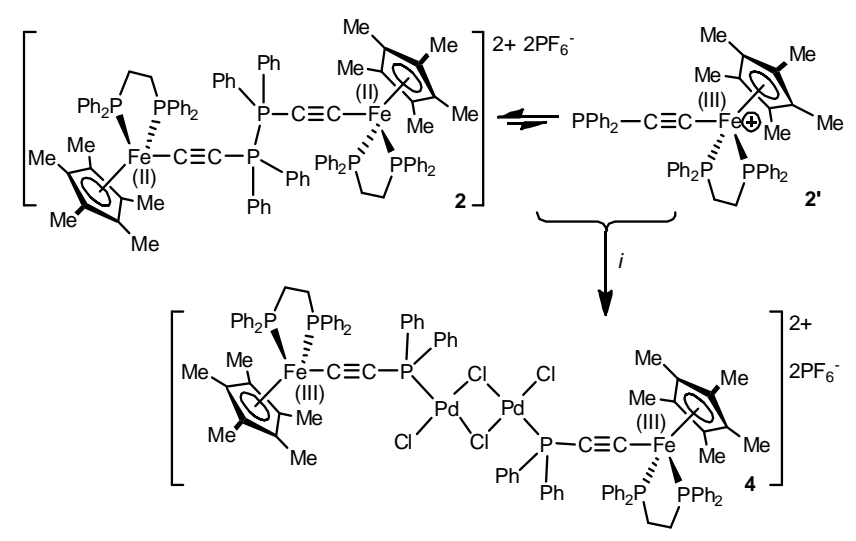

Scheme 3: Reaction of 2 with $\left[\mathrm{PdCl}_{2}(1,5-\mathrm{cod})\right]$ to generate the dicationic dimer 4. Reagents and conditions: (i) $\left[\mathrm{PdCl}_{2}(1,5\right.$-cod) $], 2$ eq., $\mathrm{CH}_{2} \mathrm{Cl}_{2}, 1 \mathrm{~h}, 20^{\circ} \mathrm{C},>98 \%$.

To conclude, metallaphosphines bearing $\left[\mathrm{Fe}\left(\kappa^{2}-\mathrm{dppe}\right)\left(\eta^{5}-\mathrm{C}_{5} \mathrm{Me}_{5}\right)\right]$ endgroups bind to $\mathrm{Pd}(\mathrm{II})$ in both their neutral and cationic forms and can therefore be used to generate a chemically stable, redox- switchable coordination sphere about $\mathrm{PdCl}_{2}$ centres. The $\left[\mathrm{Pd}(\mathrm{II})-\left(\mathbf{1}^{+}\right)_{2}\right] \leftrightarrow$ $\left[\operatorname{Pd}(\mathrm{IV})^{2+}-(\mathbf{1})_{2}\right]$ valence tautomer is firmly shifted to the left, so the metallaligand brings a potential for varying the overall electron count of the complex without excessively 
compromising the electronic identity of the palladium(II) centre. Reactivity studies of 3-6 are in progress.

\section{Notes and references}

$\dagger$ Electronic Supplementary Information (ESI) available: Full experimental, spectroscopic and crystallographic data. See DOI: 10.1039/c4dt00455h.

We thank CNRS and the French ANR (to AT, under contract BLAN 719) for support; S L thanks MNERT and ENS (Cachan) for a scholarship.

1 For the effects of ligand bite angle on the electronics of metal centres, see: M.-N. Birkholz, Z. Freixa, and P. W. N. M. van Leeuwen, Chem. Soc. Rev., 2009, 38, 1099 and literature cited.

2 P. C. J. Kamer and P. W. N. M. van Leeuwen, 'Phosphorus(III) Ligand Effects in Homogeneous Catalysis', J Wiley Chichester, 2012. M. Peruzzini and L. Gonsalvi, in 'Phosphorus Compounds', Springer Verlag, Dordrecht, 2011.

3 J. Wieland and B. Breit, Nature Chem., 2010, 2, 832. b) R. Bellini and J. N. H. Reek, Eur. J. Inorg. Chem., 2012, 4684.

4 T. Besset, D. W. Norman, and J. N. H. Reek, Adv. Synth. Catal., 2013, 355, 348.

5 a) G. Guisado-Barrios, B. K. Munoz, P. C. J. Kamer, B. Lastdrager, G. van der Marel, M. Overhand, M. Vega-Vazquez, and M. Martin-Pastor, Dalton Trans., 2013, 42, 1973, b) P. J. Deuss, R. den Heeten, W. Laan, and P. C. J. Kamer, Chem.- Eur. J., 2011, 17, 4680.

6 For instance, see : N. Avarvari, K. Kirakci, R. Llusar, V. Polo, I. Sorribes, and C. Vicent, Inorg. Chem. 2010, 49, 1894-1904; A. Labande, N. Debono, A. Sournia-Saquet, J.-C. Daran, and R. Poli, Dalton Trans., 2013, 42, 6531.

7 O. R. Luca and R. H. Crabtree, Chem. Soc. Rev., 2013, 42, 1440.

8 Non- innocent phosphorus- containing ligands are invoked relatively rarely; see for example: a) M. Vogt, M. Gargir, M. A. Iron, Y. Diskin-Posner, Y. Ben-David, and D. Milstein, Chem.- Eur. J., 2012, 18, 9194; b) M. J. Sgro and D. W. Stephan, Dalton Trans., 2011, 40, 2419; c) M. Lejeune, P. Grosshans, T. Berclaz, H. Sidorenkova, C. Besnard, P. Pattison, M. Geoffroy, New J. Chem., 2011, 35, 2510.

9 a) I. M. Lorkovic, M. S. Wrighton, W. M. Davis, J. Am. Chem. Soc., 1994, 116, 6220; b) A. M. Allgeier and C. A. Mirkin, Angew. Chem.-Int. Ed., 1998, 37, 894.

10 A. Tohmé, G. Grelaud, G. Argouarch, T. Roisnel, S. Labouille, D. Carmichael, and F. Paul, Angew. Chem.- Int. Ed., 2013, 52, 4445. For the first synthesis of 1: L. Dahlenburg, A. Weiss, M. Bock, and A. Zahl, J. Organomet. Chem., 1997, 541, 465.

11 The $\mathrm{Pd}_{2} \mathrm{Cl}_{4}$ core in 3 shows a fold angle of $35.3^{\circ}$. The butterfly configuration is wellprecedented, eg: a) P. Stepnicka, I. Cisarova, and R. Gyepes, Eur. J. Inorg. Chem. 2006, 926, as is the cisoid arrangement of the metallaphosphine $\mathrm{Cp}^{*}$ groups eg: b) L. I. Goryunov, J. Grobe, D. Le Van, V. D. Shteingarts, R. Mews, E. Lork and E.-U. 
Wurthwein, Eur. J. Org. Chem. 2010, 1111. c) S.Vuoti,,M. Haukka and J. Pursiainen, J. Organomet. Chem. 2007, 692, 5044.

12 a) K.-S. Shin and D.-Y. Noh, Bull. Korean Chem. Soc., 2008, 29, 2533; b) A. Jakob, B. Milde, P. Ecorchard, C. Schreiner, and H. Lang, J. Organomet. Chem., 2008, 693, 3821; c) T. Baumgartner, M. Fiege, F. Pontzen, and R. Arteaga-Mueller, Organometallics, 2006, 25, 5657; d) W. Oberhauser, C. Bachmann, T. Stampfl, and P. Bruggeller, Inorg. Chim. Acta., 1997, 256, 223; e) H. C. Clark, G. Ferguson, P. N. Kapoor, M. Parvez, Inorg. Chem., 1985, 24, 3924.

13 F. Paul and C. Lapinte, Coord. Chem. Rev., 1998, 178, 431.

14 For a Pd(II) to Pd(IV) oxidation using [FcH] $\left[\mathrm{PF}_{6}\right]$ see: $a$ ) J. Campora, P. Palma, D. del Rio, J. A. Lopez, E. Alvarez and N. G. Connelly, Organometallics, 2005, 24, 3624; for a more general overview of Pd(IV): b) A. J. Hickman, M. Sanford, Nature, 2012, 444, 177; c) P. Sehnal, R. J. K. Taylor, I. J. S. Fairlamb, Chem. Rev, 2010, 110, 824.

15 The geometric response of arylphosphines to a monoelectronic oxidation of their coordinated metal is well known: a) B. J. Dunne, R. B. Morris and A. G. Orpen, Dalton Trans, 1991, 653; the (marginally statistically valid) shortening of the $\mathrm{P}-\mathrm{Ph}$ mean lengths (1.838 in $\mathbf{3}, 1.832$ in 4) that is expected to accompany oxidation of the adjacent metal centre is seen at dppe but not at $\mathrm{C}_{2} \mathrm{PPh}_{2}: b$ ) A. G. Orpen, N. G. Connelly, Organometallics, 1990, 9, 1206.

16 For comparison, values for Pd-Cl trans- to phosphine in trans- $\left[\mathrm{Pd}_{2} \mathrm{Cl}_{4}\left(\mathrm{PR}_{3}\right)_{2}\right]$ are: $\mathrm{R}=\mathrm{Et}$ : 2.4444(7) H. Dialer, W. Beck, K. Polborn, given on CCDC as YARGAA; R= Ph : 2.4128(6)Å; C. Sui-Seng, F. Belanger-Gariepy, D. Zargarian Acta Cryst, E, 2003, 59, m618.

17 S. K. Sur, J. Magn. Res., 1988, 82, 169 and refs therein.

18 Taking a statistical analysis wherein all the magnetic states are equally populated, an uncoupled biradical should exhibit $75 \%$ of the magnetisation that corresponds to its triplet state (3.04 BM here with a $g$ factor of 2.15), leading to an expected value of 2.3 BM.

19 A. C. Smithies, M. Rycheck, and M. Orchin, J. Organomet. Chem., 1968, 12, 199.

20 In the models, $\mathrm{H}_{2} \mathrm{PCH}_{2} \mathrm{CH}_{2} \mathrm{PH}_{2}$ ligands replace dppe, and $\mathrm{Cp}$ replaces $\mathrm{Cp} *$. B3PW91 with $\mathrm{SDD}$ on $\mathrm{Fe}, \mathrm{Pd}$ and $\mathrm{Cl}$; SDD + polarisation on $\mathrm{P} ; 6-31 \mathrm{G}^{* *}$ for $\mathrm{C}$ and $\mathrm{H}$. See supplementary for full details.

${ }^{21}$ See supplementary. Note that the $\mathrm{Cp}^{*}$ proton shifts in $4:-8.5$ and $\mathbf{6}:-8.7 \mathrm{ppm}$ are both typical of $\left[\mathrm{Fe}^{\mathrm{III}}(\mathrm{dppe})\left(\mathrm{C}_{5} \mathrm{Me}_{5}\right)\right]^{+}$- groups. ${ }^{13}$ 